DE

M E D I C I N A

T R O P I C A L

$\mathrm{DE}$

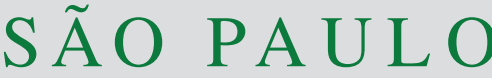

JOURNAL OF THE SÃO PAULO INSTITUTE OF TROPICAL MEDICINE

(1)Sharjah Public Health Clinic, Sharjah, United Arab Emirates

(2)University of Gezira, Faculty of Medical Laboratory Sciences, Department of Parasitology, Wad Medani, Sudan

(3)University of Sharjah, College of Health Sciences, Sharjah, United Arab Emirates

(4)University of Sharjah, College of Health Sciences, Medical Laboratory Sciences Department, Sharjah, United Arab Emirates

Correspondence to: Ali ElBakri University of Sharjah, College of Health Sciences, Medical Laboratory Sciences Department, PO Box 27272, Sharjah, United Arab Emirates

E-mail: aelbakri@sharjah.ac.ae

Received: 5 April 2017

Accepted: 1 September 2017

\section{Intestinal parasitic infections among expatriate workers in various occupations in Sharjah, United Arab Emirates}

\author{
Abdelmunim Izzeldin Abdelrahman Dafalla', Shaikha Ali Salem Obaid \\ Almuhairi', Mohamed Hassan Jasim AlHosani' ${ }^{1}$, Mira Yousif Mohamed', \\ Mariam Ibrahim Ahmed Alkous ${ }^{1}$, Mousa Abdelsattar AlAzzawi ${ }^{1}$, Adam \\ Dawoud Abakar², Bakri Yousif Mohamed Nour², Hayder Hasan ${ }^{3}$, Ra'ed Omar \\ AbuOdeh $^{4}$, Ali ElBakri ${ }^{4}$
}

\section{ABSTRACT}

Intestinal parasitic infections are prevalent throughout many countries. This study aimed to determine the prevalence of intestinal parasite carriers among 21,347 expatriate workers, including food handlers and housemaids attending the public health center laboratory in Sharjah, UAE. Stool sample collection was performed throughout the period between January and December 2013. All samples were examined microscopically. Demographic data were also obtained and analyzed. Intestinal parasites were found in 3.3\% (708/21,347) of the studied samples (single and multiple infections). Among positive samples, six hundred and eighty-three samples (96.5\%) were positive for a single parasite: Giardia lamblia (257; $36.3 \%$ ) and Entamoeba histolytica/Entamoeba dispar (220;31.1\%), respectively, whereas mono-infections with helminths accounted for $206(29.1 \%)$ of the samples. Infection rates with single worms were: Ascaris lumbricoides (84; 11.9\%), Hookworm (34; 4.8\%), Trichuris trichiura $(33 ; 4.7 \%)$, Taenia spp. $(27 ; 3.81 \%)$, Strongyloides stercoralis $(13$; $1.8 \%)$, Hymenolepis nana $(13 ; 1.8 \%)$, and Enterobius vermicularis $(2 ; 0.28 \%)$, respectively. Infections were significantly associated with gender $\left(x^{2}=14.18 ; p=0.002\right)$ with males as the most commonly infected with both groups of intestinal parasites (protozoa and helminths). A strong statistical association was noted correlating the parasite occurrence with certain nationalities $\left(x^{2}=49.5, \mathrm{p}<0.001\right)$. Furthermore, the study has also found a strong statistical correlation between parasite occurrence and occupation $\left(x^{2}=15.60 ; \mathrm{p}=0.029\right)$. Multiple infections were not common (3.5\% of the positive samples), although one individual $(0.14 \%)$ had four helminth species, concurrently. These findings emphasized that food handlers with different pathogenic parasitic organisms may pose a significant health risk to the public.

KEYWORDS: Intestinal parasites. Intestinal parasitic infections. Helminths. Protozoa. Expatriates. Hygiene. Sharjah.

\section{INTRODUCTION}

Intestinal parasitic infections are a major cause of morbidity and mortality to the public health, particularly in developing countries ${ }^{1}$. The spread of parasites is closely related to educational, environmental, sanitary conditions, socio-economic status, inadequate medical care and absence of safe drinking water supplies ${ }^{2}$. Asymptomatic food handlers and housemaids are a potential source of infection for many intestinal parasites and other enteropathogenic infections ${ }^{3,4}$. The transmission of parasites occurs directly or indirectly through food, water or hands, reinforcing the 
importance of fecal-oral and human-to-human transmission modes $^{5}$. Thus, food handlers with poor personal hygiene and inadequate knowledge on food safety could be the source of foodborne pathogens and may be implicated in the transmission of many infections to the local community ${ }^{4,6,7}$. Laborers, chefs, housemaids and drivers are an important group of economic migrants who normally harbor and carry parasitic infections with them to the countries where they settle in ${ }^{8}$. Furthermore, infected immigrants or travelers returning to their employment in the food business pose an infection risk to the public.

In the UAE, most expatriates working as food handlers, drivers, housemaids and child/elderly-care assistants originate from endemic regions of intestinal parasites, modest socio-economic levels and do not have acess to adequate medical care. Consequently, it would be important to alert both, expatriates and the local community, on the risk of contracting contagious parasitic infections.

Many reports have been published on the extent of intestinal parasitic infections among expatriates including immigrant food handlers, housemaids and laborers in the Arabian Gulf countries ${ }^{9-15}$. In the UAE, however, limited studies have investigated the prevalence of intestinal parasites among expatriates and UAE nationals ${ }^{16-19}$. Therefore, the aim of this study was to ascertain the distribution and prevalence of various intestinal parasites in immigrants applying for diverse jobs and careers in Sharjah, UAE.

\section{MATERIALS AND METHODS}

This is a retrospective cross-sectional study concerning the prevalence of intestinal parasites among immigrant workers in certain jobs (food handlers, babysitters, housemaids, private cooks and drivers) arriving to work in Sharjah during the period between January and December 2013. A convenient sampling method was used to enroll all workers tested in the designated period. Stool samples were collected from healthy immigrant workers attending the Sharjah City Municipality Public Health Clinic (SCMPHC) for routine health examination before the beginning of work activities. Age, sex, and nationality were recorded for each individual. Approval to use the data to conduct this study was sought from the Sharjah Public Health Director. Fresh fecal samples were collected in $25 \mathrm{~mL}$ clean, wide-mouthed, covered plastic containers (no preservative). Each sample was labeled with a unique identification reference of the individual who providing it. Stool samples were examined using direct smear after staining with Lugol's iodine (1\%) to investigate the presence of parasite eggs/cysts/ larval stages. One slide per individual was examined by one trained technologist. Statistical analyses were performed using SPSS version 17.0 (SPSS, Chicago, IL). Variables were expressed as numbers and percentages to determine the distribution and prevalence of various intestinal parasitic infections. The Chi-square test was applied to examine the dependency of the parasitic infection on the sex, nationality and occupation of the patient. A $p$ value $<0.05$ was considered statistically significant.

\section{RESULTS}

Twenty-one thousand, three hundred and forty-seven samples $(18,145,85 \%$ males; and 3,202, 15\% females) were screened for intestinal parasites, of which $3.3 \%$ (708/21,347) were positive. Males with positive results were $88.64 \%$ (628/708), whereas $11.36 \%$ (80/708) were females yielding a ratio of nearly 8:1 (Table 1). Participants were categorized according to the nature of their occupational activities. Fifty percent (354/708) were food handlers, followed by $16.6 \%$ (118/708) of laborers, $14.7 \%$ (104/708) of salesmen, $11.6 \%$ (82/708) of housemaids, $1.6 \%(11 / 708)$ of drivers and 5.5\% (39/708) of people working in other occupations. Food handlers included: bakers, waiters, butchers, and cooks, in addition to those involved in preparing tea, sandwiches, juices, and sweets. Other occupations included: packers, clothes pressers, messengers, storekeepers and cashiers. The frequency of country of origin of those identified as positive were as follows: India (215/708; 30.4\%), Bangladesh (146/708; 20.6\%), Pakistan (114/708; 16.1\%), Afghanistan (84/708; 11.9\%), Nepal (44/708; 6.2\%), Philippines (44/708; 6.2\%), Sri Lanka (15/708; $2.1 \%)$, Egypt (13/708; 1.8\%), Ethiopia $(11 / 708 ; 1.6 \%)$, Indonesia $(11 / 708 ; 1.6 \%)$, Iran (4/708; $0.6 \%)$, Syria (4/708, $0.6 \%)$, Jordan $(1 / 708 ; 0.1 \%)$, Kenya $(1 / 708 ; 0.1 \%)$ and Tanzania $(1 / 708 ; 0.1 \%)$.

Intestinal parasites were divided into two main groups: protozoa and helminths. The protozoa group consisted of G. lamblia and E. histolytica/E. dispar only, whereas the helminth group comprised of all identified worm infections. Single infections were identified in $96.5 \%$ (683/708) of samples while double infections were found in $3.36 \%$ (24/708) of samples and only one participant $(0.14 \%$ $1 / 708$ ) had quadruple infection. Singly identified intestinal parasites were then arranged into two main clusters, the protozoa group (G. lamblia and E. histolyticalE. dispar) and the helminth group (A. lumbricoides, Hookworms, T. trichiura, Taenia spp., S. stercoralis, H. nana, and $E$. vermicularis) (Table 2). About $27 \%$ of those identified as positive aged between $16-25$ years, $46.2 \%$ aged between 26-34 years, while $17.6 \%$ were $35-43$ years old and $9.2 \%$ were above 44 years old (Table 2). Analysis of the 
Table 1 - Pattern and distribution of intestinal parasitic infections among 708 positive samples as determined by gender

\begin{tabular}{|c|c|c|c|}
\hline Intestinal Parasites & $\begin{array}{c}\text { Females } \\
\mathrm{N}(\%)\end{array}$ & $\begin{array}{l}\text { Males } \\
\mathrm{N}(\%)\end{array}$ & $\begin{array}{l}\text { Total } \\
\text { N (\%) }\end{array}$ \\
\hline Single Infection & $76(10.8)$ & $607(85.7)$ & $683(96.5)$ \\
\hline Double Infection & $4(0.56)$ & $20(2.8)$ & $24(3.36)$ \\
\hline A. lumbricoides + E. histolytica/E. dispar & - & $2(0.28)$ & $2(0.28)$ \\
\hline A. lumbricoides + G. lamblia & - & $5(0.7)$ & $5(0.7)$ \\
\hline A. lumbricoides + T. trichiura & - & $2(0.28)$ & $2(0.28)$ \\
\hline E. histolytica/E. dispar + G. lamblia & $2(0.29)$ & $5(0.7)$ & $7(0.99)$ \\
\hline E. histolytica/E. dispar + Taenia spp. & $1(0.14)$ & - & $1(0.14)$ \\
\hline G. lamblia + S. stercoralis & - & $1(0.14)$ & $1(0.14)$ \\
\hline G. lamblia + T. trichiura & - & $1(0.14)$ & $1(0.14)$ \\
\hline G. lamblia + Taenia spp. & - & $1(0.14)$ & $1(0.14)$ \\
\hline Hookworm + G. lamblia & - & $1(0.14)$ & $1(0.14)$ \\
\hline Hookworm + T. trichiura & $1(0.14)$ & - & $1(0.14)$ \\
\hline Hookworm + Taenia spp. & - & $2(0.28)$ & $2(0.28)$ \\
\hline Quadruple Infection & & & $1(0.14)$ \\
\hline T. trichiura + S. stercoralis $+H$. nana + Hookworm & - & $1(0.14)$ & $1(0.14)$ \\
\hline Total & $80(11.36)$ & $628(88.64)$ & 708 \\
\hline
\end{tabular}

distribution of intestinal parasites among the various age groups showed no significant association between the two variables $\left(\chi^{2}=34.93, \mathrm{P}=0.656\right)$.

As shown in Table 3, infection with both parasite groups (protozoa and helminths) was significantly higher among males than in females $\left(\chi^{2}=14.18 ; \mathrm{P}=0.002\right)$. The protozoa group infection was more frequent in males than in females [88.7\% (423/477) vs. 11.3\% (54/477)]. Similarly, the helminth group infection was higher in males than in females [89.3\% (184/206) vs. $10.7 \%(22 / 206)]$. It is evident that males were more less frequently singly infected with either group of intestinal parasites. However, it is important to point out that this was maybe simply a result of more males being tested. Further analysis of the 683 stool samples that were positive for a single parasitic infection only in relation to the participants' countries of origin showed that $34.7 \%$ of all positive protozoa samples were from the Indian workers, whereas $27.2 \%$ of the positive helminth samples were from individuals from Bangladesh. On the other hand, workers from Jordan, Kenya and Tanzania showed $0.2 \%$ of all protozoa positive samples with none of them positive for helminths (Table 4). While a statistically significant difference between subjects from different geographical origins was observed $\left(\chi^{2}=49.5, \mathrm{P}=<0.001\right)$, it is probable that this is due to the fact that more national citizens from certain countries were involved in the analysis (Indians and Bangladeshis in this case) compared to individuals from other nationalities. The occurrence of parasites was associated with the occupational category $\left(\chi^{2}=15.60\right.$, $\mathrm{P}=0.029)$. The highest mono-infection rates were noted among food handlers, in whom the protozoa and helminth incidences were detected in 121 (58.7\%) and 216 (45.3\%) individuals, respectively, were followed by laborers 31 (15.0\%) and 85 (17.8\%). Likewise, this may be due to more workers applying for the above mentioned occupations.

\section{DISCUSSION}

In the present study, the overall prevalence of intestinal parasites detected among expatriates in Sharjah was $3.3 \%$. An earlier study conducted in Sharjah, investigated intestinal parasites infection rates among both expatriates and locals, and the infection rate was reported as $7.7 \%{ }^{19}$. The prevalence of intestinal parasitic infections in the current study was also considerably lower than those

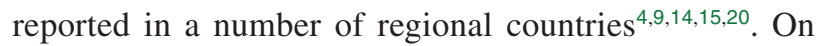
the other hand, the overall prevalence of protozoa and helminths, including mixed infections was $2.3 \%$ and $1.0 \%$, respectively. Unlike the present study, a higher prevalence was reported for both protozoa $(24.8 \%)$ and helminths $(13.6 \%)$ in a similar Qatari study ${ }^{9}$. Furthermore, an Iranian study reported a protozoan prevalence of $15.1 \%$ and worms' infection rate of $0.4 \%$ among food handlers in Sari, Northern Iran ${ }^{4}$. The prevalence of helminths in the present study is to some extent similar to that reported by Sharif and colleagues ${ }^{4}$. The overall comparative decrease in the 
Table 2 - Percentage distribution of intestinal parasitic infections as determined by age groups regarding all positive samples $(\mathrm{n}=708)$

\begin{tabular}{|c|c|c|c|c|c|c|}
\hline \multirow{2}{*}{\multicolumn{2}{|c|}{ Intestinal Parasite }} & \multirow[b]{2}{*}{$\mathrm{N}(\%)$} & \multicolumn{4}{|c|}{ Age Group (years) } \\
\hline & & & \multirow{2}{*}{$\begin{array}{r}16-25 \\
\mathrm{~N}(\%) \\
\end{array}$} & \multirow{2}{*}{$\begin{array}{l}26-34 \\
\mathrm{~N}(\%) \\
\end{array}$} & \multirow{2}{*}{$\begin{array}{l}35-43 \\
\mathrm{~N}(\%) \\
\end{array}$} & \multirow{2}{*}{$\begin{array}{l}>44 \\
\mathrm{~N}(\%) \\
\end{array}$} \\
\hline \multirow{12}{*}{$\begin{array}{l}\text { Single } \\
\text { Infection }\end{array}$} & Protozoa group [477 (67.4\%)] & & & & & \\
\hline & G. lamblia & $257(36.3)$ & $73(10.31)$ & $126(17.8)$ & $38(5.37)$ & $20(2.82)$ \\
\hline & E. histolytica/E. dispar & $220(31.1)$ & $60(8.5)$ & $91(12.85)$ & $41(5.8)$ & $28(3.95)$ \\
\hline & Helminths group [206 (29.1\%)] & & & & & \\
\hline & A. lumbricoides & $84(11.9)$ & $20(2.82)$ & $42(5.96)$ & $19(2.7)$ & $3(0.42)$ \\
\hline & Hookworm & $34(4.8)$ & $8(1.13)$ & $17(2.4)$ & $6(0.85)$ & $3(0.42)$ \\
\hline & T. trichiura & $33(4.7)$ & $9(1.31)$ & $12(1.7)$ & $8(1.13)$ & $4(0.56)$ \\
\hline & Taenia spp. & $27(3.81)$ & $7(0.99)$ & $12(1.7)$ & $5(0.7)$ & $3(0.42)$ \\
\hline & S. stercoralis & $13(1.8)$ & $3(0.42)$ & $6(0.83)$ & $3(0.42)$ & $1(0.14)$ \\
\hline & H. nana & $13(1.8)$ & $2(0.28)$ & $10(1.4)$ & $1(0.14)$ & $0(0.0)$ \\
\hline & E. vermicularis & $2(0.28)$ & $0(0.0)$ & $1(0.14)$ & $0(0.0)$ & $1(0.14)$ \\
\hline & Total & $683(96.5)$ & $182(25.7)$ & $317(44.8)$ & $121(17.1)$ & $63(8.9)$ \\
\hline \multirow{12}{*}{$\begin{array}{l}\text { Double } \\
\text { Infection }\end{array}$} & A. lumbricoides + E.histolyticalE. dispar & $2(0.28)$ & $0(0)$ & $2(10.28)$ & $0(0)$ & $0(0)$ \\
\hline & A. lumbricoides + G. lamblia & $5(0.7)$ & $2(0.28)$ & $0(0)$ & $2(0.28)$ & $1(0.14)$ \\
\hline & A. lumbricoides + T. trichiura & $2(0.28)$ & $1(0.14)$ & $1(0.14)$ & $0(0)$ & $0(0)$ \\
\hline & E. histolytica/E. dispar + G. lamblia & $7(0.99)$ & $3(0.42)$ & $2(0.28)$ & $1(0.14)$ & $1(0.14)$ \\
\hline & E. histolyticalE. dispar + Taenia spp. & $1(0.14)$ & $1(0.14)$ & $0(0)$ & $0(0)$ & $0(0)$ \\
\hline & G. Iamblia + S. stercoralis & $1(0.14)$ & $0(0)$ & $0(0)$ & $1(0.14)$ & $0(0)$ \\
\hline & G. Iamblia + T. trichiura & $1(0.14)$ & $0(0)$ & $1(0.14)$ & $0(0)$ & $0(0)$ \\
\hline & G. lamblia + Taenia spp. & $1(0.14)$ & $0(0)$ & $1(0.14)$ & $0(0)$ & $0(0)$ \\
\hline & Hookworm + G. lamblia & $1(0.14)$ & $1(0.14)$ & $0(0)$ & $0(0)$ & $0(0)$ \\
\hline & Hookworm + T. trichiura & $1(0.14)$ & $0(0)$ & $1(0.14)$ & $0(0)$ & $0(0)$ \\
\hline & Hookworm + Taenia spp. & $2(0.28)$ & $0(0)$ & $2(0.28)$ & $0(0)$ & $0(0)$ \\
\hline & Total & 24 (3.36) & $8(1.12)$ & $10(1.4)$ & $4(0.56)$ & $2(0.28)$ \\
\hline \multirow{2}{*}{$\begin{array}{l}\text { Quadruple } \\
\text { Infection }\end{array}$} & T. trichiura + S. stercoralis + H. nana + Hookworm & $1(0.14)$ & $1(0.14)$ & $0(0)$ & $0(0)$ & $0(0)$ \\
\hline & Total & $1(0.14)$ & $1(0.14)$ & 0 & 0 & 0 \\
\hline Grand Total & & 708 & $191(26.98)$ & $327(46.21)$ & $125(17.61)$ & $65(9.2)$ \\
\hline
\end{tabular}

Table 3 - Association of the type of intestinal parasitic infections (protozoa and helminth groups) with sex, among the 683 singly infected samples using the Chi-square test

\begin{tabular}{llcccc}
\hline \multirow{2}{*}{ Intestinal Parasite } & $\mathrm{N}$ & \multicolumn{2}{c}{ Gender } & \multirow{2}{*}{$\chi^{2}$ Test } & $p$-value \\
\cline { 3 - 4 } & & Male $(\mathrm{N}=607)$ & Female $(\mathrm{N}=76)$ & & 0.002 \\
\hline Protozoa Group & 477 & $423(88.7 \%)$ & $54(11.3 \%)$ & 14.18 & \\
Helminths Group & 206 & $184(89.3 \%)$ & $22(10.7 \%)$ & & \\
\hline
\end{tabular}

number of positive samples in the current study could be due to several factors, the main one being the overwhelming number of samples reaching the laboratory on a daily basis, being tested by few laboratory personnel. This alone can affect the quality of the work and the time usually spent per sample. In addition, stool samples to be tested for parasites are not usually handled by the same skilled personnel with adequate experience in parasites identification.

Among the 708 positive samples, 683 (96.5\%) were infected with a single parasite and $25(3.5 \%)$ with multiple parasites. Of the 683 mono-infections, $67.4 \%$ were infected with protozoa and $29.1 \%$ with helminths. This is in disagreement with a previous Sharjah study in which Dash et al. reported an overall prevalence of protozoa and 
Table 4 - Distribution of the intestinal parasitic infections (protozoa and helminth groups) according to nationality

\begin{tabular}{|c|c|c|c|c|}
\hline \multirow[b]{2}{*}{ Nationality } & \multicolumn{2}{|c|}{ Type of Infection } & \multirow[b]{2}{*}{ Chi-square $\left(\chi^{2}\right)$} & \multirow[b]{2}{*}{$P$ value } \\
\hline & $\begin{array}{c}\text { Protozoa }(\mathrm{N}=470) \\
\mathrm{N}(\%)\end{array}$ & $\begin{array}{c}\text { Helminths }(\mathrm{N}=213) \\
\mathrm{N}(\%)\end{array}$ & & \\
\hline Afghan & $34(7.2)$ & $44(20.7)$ & & \\
\hline Bangladesh & $82(17.4)$ & $58(27.2)$ & & \\
\hline Egypt & $10(2.1)$ & $3(1.4)$ & & \\
\hline Ethiopia & $7(1.5)$ & $4(1.9)$ & & \\
\hline India & $163(34.7)$ & $47(22.1)$ & 49.5 & $<0.001$ \\
\hline Indonesia & $7(1.5)$ & $4(1.9)$ & & \\
\hline Iran & $4(0.9)$ & $0(0)$ & & \\
\hline Jordan & $1(0.2)$ & $0(0)$ & & \\
\hline Kenya & $1(0.2)$ & $0(0)$ & & \\
\hline Nepal & $33(7.0)$ & $9(4.2)$ & & \\
\hline Pakistan & $83(17.7)$ & $28(13.1)$ & & \\
\hline Philippines & $27(5.7)$ & $14(6.6)$ & & \\
\hline SriLanka & $14(3.0)$ & $1(0.5)$ & & \\
\hline Syria & $3(0.6)$ & $1(0.5)$ & & \\
\hline Tanzania & $1(0.2)$ & $0(0)$ & & \\
\hline
\end{tabular}

helminth infections of $92.2 \%$ and $7.8 \%$, respectively ${ }^{19}$. The referred study used data from hospitalized patients instead of healthy individuals. Furthermore, hospital data were gathered from patients belonging to different socioeconomic levels, including the wealthiest. Furthermore, the hospital laboratory uses a concentration technique to investigate parasites which usually yields better results.

Mono-infections with parasitic worms identified in the present study were similarly prevalent with respect to observations previously reported in neighboring countries $^{21,22}$. A similar Saudi study conducted in AlMadinah Al-Munawarah, reported a significantly lower frequencies of G. lamblia (21.9\%) and E. histolyticalE. coli $(17.8 \%)$ than those reported in this report ${ }^{15}$. Furthermore, the infection rates with helminths in the current study (Table 2) were significantly lower than the ones from the Saudi report by Taha et al. ${ }^{15}$. It is possible that the low overall prevalence observed in the present study could be explained by the different geographic origins of the participants, personal hygiene, collection time of the stool sample, previous anti-parasitic treatment, technicians' skills, a decrease over time of the prevalence of parasites in many countries due to control programs, environmental improvements and the low parasite density making it easy to have false-negative results by microscopy.

Although a significant association was observed between gender and parasite groups (the frequency of males infected with parasites was higher than in females), it is probable that this correlation was due to the large number of males screened in the study in comparison to females (Table 3). Nevertheless, and similar to our results, several studies have stated higher prevalences in males than in females ${ }^{4,23,24}$. In comparison to a study by Taha et al. ${ }^{15}$ in $\mathrm{Al}$ Madinah Al-Munawarah, Saudi Arabia, protozoa infections detected in this investigation were significantly higher in males than in females. This could be attributed to the fact that, in UAE and neighboring countries, males represent the bulk of the labor force in food industry and related jobs.

Like in previous regional studies, no significant association was noted between the parasitic infection and age groups. Nonetheless, the 26-34 year age group harbored most of the common parasitic infections (46.21\%), while individuals $>44$ years $(9.2 \%)$ were the least infected (Table 2). Similar studies reported no significant differences in the distribution of parasitic infections among age groups ${ }^{4,15}$. This shows that there is equal exposure to infection and suggests an effect of environmental conditions on infection ${ }^{4,5,25}$.

Furthermore, the present study revealed a preponderance of participants from certain countries regarding parasitic infections. High infection rates were observed among Indian workers, followed by Bangladeshis, Pakistanis and Afghans. A significant statistical association was observed between parasite occurrence and individuals from different countries $\left(\chi^{2}=49.5, p=<0.001\right)$. It is important to state here that individuals from the countries with the highest infection 
rates in this study, in general, form the largest group of expatriates in the UAE and surroundings. Contrary to the present report, Taha et al. ${ }^{15}$ in Al-Madinah Al-Munawarah, Saudi Arabia, reported Pakistani workers as the nationality with the highest infection rate (23.2\%), followed by Filipino workers $(22,2 \%)$, and Sudanese individuals (18.7\%), while the lowest infection rate was recorded in Bangladeshi individuals (3.8\%) with a significant variation.

A strong significant association between parasite occurrence and occupation was also noted $\left(\chi^{2}=15.60\right.$, $p=0.029)$. Food handlers were the most infected group [protozoa (58.7\%); helminths $(45.3 \%)$ ], whereas cleaners (protozoa, $1.5 \%$ ) and drivers (helminths; $1.5 \%$ ) were the least infected. Nonetheless, a similar population of expatriates in Al-Madinah Al-Munawarah, Saudi Arabia, reported the highest infection rates among farmers followed by food handlers, shepherds, drivers and housemaids ${ }^{15}$. Like the present investigation, a significant association between the prevalence of intestinal parasites and occupation was observed. Once more, this could be attributed to the large number of workers applying for jobs in the food industry.

One significant finding in the current study was the low prevalence of intestinal parasites in the overall study population (3.3\%). Even if this low frequence is comparable to results from other studies carried out in the region and afar, it nevertheless raises concerns about the time spent examining the sample, the overall workload and the number of samples requested from each individual (normally three) before a sample is reported negative for parasites. All these factors can result in false negatives possibly leading to the spread of infections.

Whereas the current study was the first comprehensive one to address the issue of parasites prevalence in a healthy expatriate population, the investigation suffered from certain limitations, such as the lack of data from similar centers in other regions of the UAE, scarcity of figures from the local community to compare with expatriate data and the need to include other detection methods to enhance results accuracy.

Although the analysis revealed a low overall prevalence of intestinal parasitic infections in comparison to other regional studies, regular community-based awareness and health educational programs should also be considered especially in the food handling segments of the expatriate population, since they may contribute as a source of intestinal parasitic infections for the community, even in countries where there is effective disease control. Based on the current findings, the authors recommend that, to improve the efficiency of work and increase parasite detection sensitivity, several measures can be taken such as technicians' training, performing the ethyl acetate concentration method, the introduction of other methods such as antigen detection and molecular techniques, increasing the number of laboratory personnel to meet the work load demands, and regular follow-up inspections to reduce the risk of spread of infections from migrant workers to the public.

\section{ACKNOWLEDGEMENTS}

The authors would like to thank Dr. Al Mutaz Mohamed Abdalla, Health Information Management Office, Tawam Hospital, UAE, for his help with data analysis and review.

\section{CONFLICT OF INTEREST}

The authors declare no conflict of interest related to this study.

\section{REFERENCES}

1. Savioli L, Albonico M, Engels D, Montresor A. Progress in the prevention and control of schistosomiasis and soil-transmitted helminthiasis. Parasitol Int. 2004;53:103-13.

2. Celiksöz A, Güler N, Güler G, Oztrop AY, Degerli S. Prevalence of intestinal parasites in three socioeconomically-different regions of Sivas, Turkey. J Health Popul Nutr. 2005;23:184-91.

3. Andargie G, Kassu A, Moges F, Tiruneh M, Huruy K. Prevalence of bacteria and intestinal parasites among food-handlers in Gondar town, northwest Ethiopia. J Health Popul Nutr. 2008;26:451-5.

4. Sharif M, Daryani A, Kia E, Rezaei F, Nasiri M, Nasrolahei M. Prevalence of intestinal parasites among food handlers of Sari, Northern Iran. Rev Inst Med Trop Sao Paulo. 2015;57:139-44.

5. Zaglool DA, Khodari YA, Othman RA, Farooq MU. Prevalence of intestinal parasites and bacteria among food handlers in a tertiary care hospital. Niger Med J. 2011;52:266-70.

6. Takalkar AA, Madhekar NS, Kumavat AP, Bhayya SM. Prevalence of intestinal parasitic infections amongst food handlers in hotel and restaurants in Solapur city. Indian J Public Health. 2010;54:47-8.

7. Kheirandish F, Tarahi MJ, Ezatpour B. Prevalence of intestinal parasites among food handlers in Western Iran. Rev Inst Med Trop Sao Paulo. 2014;56:111-4.

8. Wang LC. Changing patterns in intestinal parasitic infections among Southeast Asian laborers in Taiwan. Parasitol. Res. 2004;92:18-21.

9. Abu-Madi MA, Behnke JM, Ismail A. Patterns of infection with intestinal parasites in Qatar among food handlers and housemaids from different geographical regions of origin. Acta Trop. 2008;106:213-20. 
10. Idris MA, Al-Awfy SA. Parasitic infections in a pre-screening of food handlers in the Sultanate of Oman. Med Newsl. 1990;6:20-3.

11. Idris AA, Shaban MA. Changing patterns of intestinal parasitic infections among school children, outpatients and food handlers in Salalah, Dhofar (1981-1989). Oman Med J. 1992;9:32-5.

12. Ali SI, Jamal K, Qadri SM. Prevalence of intestinal parasites among food handlers in Al-Medinah. Ann Saudi Med. 1992;12:63-6.

13. Al-Madani AA, Mahfouz AA. Prevalence of intestinal parasitic infections among Asian female house keepers in Abha District, Saudi Arabia. Southeast Asian J Trop Med Public Health. 1995;26:135-7.

14. Abahussain NA. Prevalence of intestinal parasites among expatriate workers in Al-Khobar, Saudi Arabia. Middle East J Fam Med. 2005;3:1-4.

15. Taha HA, Soliman MI, Banjar SA. Intestinal parasitic infections among expatriate workers in Al-Madina Al-Munawarah, Kingdom of Saudi Arabia. Trop Biomed. 2013;30:78-88.

16. AbuOdeh R, Ezzedine S, Samie A, Stensvold C R, ElBakri A. Prevalence and subtype distribution of Blastocystis in healthy individuals in Sharjah, United Arab Emirates. Infect Genet Evol. 2016;37:158-62.

17. ElBakri A, Samie A, Bessong P, Potgieter N, AbuOdeh R. Detection and molecular characterisation of Giardia lamblia genotypes in Sharjah, United Arab Emirates. Trans R Soc Trop Med Hyg. 2014;108:466-73.
18. ElBakri A, Samie A, Ezzedine S, AbuOdeh R. Differential detection of Entamoeba histolytica, Entamoeba dispar and Entamoeba moshkovskii in fecal samples by nested PCR in the United Arab Emirates (UAE). Acta Parasitol. 2013;58:185-90.

19. Dash N, Al-Zarouni M, Anwar K, Panigrahi D. Prevalence of intestinal parasitic infections in Sharjah, United Arab Emirates. Hum Parasit Dis 2010;2:21-4.

20. Astal Z. Epidemiological survey of the prevalence of parasites among children in Khan Younis governorate, Palestine. Parasitol Res. 2004;94:449-51.

21. Al-Madani AA, Omar MS, Abu-Zeid HA, Abdulla SA. Intestinal parasites in urban and rural communities of Abha, Saudi Arabia. Ann Saudi Med. 1989;9:182-5.

22. Korkes F, Kumagai FU, Belfort RN, Szejnfeld D, Abud TG, Kleinman A. Relationship between intestinal parasitic infection in children and soil contamination in an urban slum. J Trop Pediat. 2008;55:42-5.

23. Nasiri V, Esmailnia K, Karim G, Nasir M, Akhavan O. Intestinal parasitic infections among inhabitants of Karaj city, Tehran province, Iran in 2006-2008. Korean J Parasitol. 2009;47:265-8.

24. Ekdahi K, Andersson Y. Imported giardiasis: impact of international travel, immigration, and adoption. Am J Trop Med Hyg. 2005;72:825-30.

25. Suriptiastuti HJ, Manan WS. Intestinal parasites from fingernails of sidewalk food vendors. Universa Med. 2011;30:120-5. 